\title{
A comparative study of the proton transport properties of metal (IV) tungstates
}

\author{
ALPANA PARIKH and UMA CHUDASAMA* \\ Applied Chemistry Department, Faculty of Technology and Engineering, \\ M S University of Baroda, Vadodara 390 001, India \\ e-mail: vishuma99@yahoo.co.in
}

MS received 16 March 2002; revised 7 October 2002

\begin{abstract}
Tetravalent metal acid (TMA) salts are cation exchangers due to the presence of structural hydroxyl groups. The presence of protons makes the TMA salt, a potential candidate for solid state protonic conduction. In the present endeavour, amorphous inorganic ion exchangers of the class of TMA salts, tin tungstate ( $\mathrm{SnW})$, titanium tungstate (TiW) and zirconium tungstate $(\mathrm{ZrW})$ have been synthesized and characterized for elemental analysis, thermal analysis (TGA, DSC), FTIR spectroscopy and X-ray analysis. Chemical resistivity of these materials have been assessed in various acidic, basic and organic media. Ion exchange capacity has been determined and effect of heating on ion exchange capacity has been studied. The proton conduction behaviour of these materials has been studied by measuring specific conductance $(\sigma)$ at different temperatures in the range $30-175^{\circ} \mathrm{C}$ using HP $4192 \mathrm{~A}$ impedance analyzer. The specific conductance values for the three materials have been compared.
\end{abstract}

Keywords. Tetravalent metal acid salts; inorganic ion exchangers; proton conduction; metal (IV) tungstates; transport properties.

\section{Introduction}

In recent years, there has been intense research aimed at discovering new proton conductors and the mechanism of conduction in solids. Materials with high and pure protonic conductivity are candidates for electrolytes in sensors, batteries, fuel cells, electrolysers, etc. An entire class of materials has gained increasing interest as proton conductors: Polymers, oxide ceramics, intercalation compounds etc. Recently, a brief overview of the past and present state of solid state protonic conductors has been reported. ${ }^{1,2}$

Protonic conductors are often considered to be electrolytes in which hydrogen is transported towards and evolved at the cathode during electrolysis. Protonic transport includes transport of protons $\left(\mathrm{H}^{+}\right)$and any assembly that carries protons $\left(\mathrm{OH}^{-}, \mathrm{H}_{2} \mathrm{O}, \mathrm{H}_{3} \mathrm{O}^{+}, \mathrm{NH}_{4}^{+}\right.$, $\mathrm{HS}^{-}$etc.). The transport of protons $\left(\mathrm{H}^{+}\right)$between relatively stationary host anions is termed the 'Grothus' or 'free-proton mechanism'. Transport by any of other species is termed as a 'vehicle mechanism'. ${ }^{3}$ In solids, vehicle mechanisms are usually restricted to materials with open structures (channels, layers) to allow passage of the large ions and molecules, while the Grothus mechanism requires close proximity of water molecules

*For correspondence 
which are held firmly but are able to rotate. The classification of proton conductors according to the preparation method, chemical composition, structural dimensionality, mechanism of conduction etc. have been summarized in a comprehensive book on proton conductors. ${ }^{4}$

Inorganic ion exchangers of the class of TMA salts have been extensively studied in the field of separation science and catalysis. However, attempts have also been made to study the transport properties of these materials. ${ }^{5,6}$ The mechanism of diffusion and ionic transport in crystalline $\alpha$-zirconium phosphate has been studied in detail. ${ }^{6}$ TMA salts have the general formula $\mathrm{M}(\mathrm{IV})\left(\mathrm{HXO}_{4}\right)_{2} \cdot n \mathrm{H}_{2} \mathrm{O}$ where $\mathrm{M}(\mathrm{IV})=\mathrm{Zr}$, Ti, Th, Ce, Sn, etc. and $\mathrm{X}=\mathrm{P}, \mathrm{Mo}, \mathrm{W}, \mathrm{As}, \mathrm{Sb}$, etc. The number of water molecules depend upon the method of preparation, drying conditions etc. They possess structural hydroxyl protons, which are responsible for their ion exchange behaviour. When these - $\mathrm{OH}$ groups are hydrated, the protons can easily move on the surface, thus accounting for their conductivities which depend strongly on relative humidity, the surface area and the degree of crystallinity. ${ }^{7}$ From our laboratory we have reported protonic conduction behaviour of amorphous zirconium phosphomolybdate and its single salt counter parts, zirconium phosphate and zirconium molybdate. ${ }^{8}$ Literature survey reveals that no work has been done on the proton conduction behaviour of tungstates of tin, titanium and zirconium.

In the light of the recent advances in the field of protonic conduction, the present study includes synthesis, characterization and study of transport properties of metal (IV) tungstates, $\mathrm{SnW}$, TiW and $\mathrm{ZrW}$. The materials have been characterized for elemental analysis, thermal analysis (TGA, DSC), FTIR spectroscopy, X-ray analysis and surface area measurements (BET method). Chemical stability of these materials have been assessed in various acidic, basic and organic media. Ion exchange capacity has been determined and effect of heating on ion exchange capacity studied. Further, protonic conductivities in these materials have been measured at various temperatures and the specific conductance values for these materials compared.

\section{Experimental}

\subsection{Preparation of the materials ( $\mathrm{SnW}, \mathrm{TiW}$ and $\mathrm{ZrW})$}

The materials SnW, TiW and $\mathrm{ZrW}$ were prepared by adding aqueous solution of sodium tungstate $(0.2 \mathrm{M}, 100 \mathrm{ml})$ to aqueous solution of metal salts in chloride form $(0 \cdot 1 \mathrm{M}$, $100 \mathrm{ml}$ ) dropwise and with continuous stirring. The $\mathrm{pH}$ of the resulting solution along with the gel obtained was maintained at $\sim 2 \mathrm{pH}$ and allowed to stand for at least $24 \mathrm{~h}$, filtered, washed with conductivity water till free of chloride ions and dried at room temperature. The dried materials were brought to the desired particle size (60-100 mesh) and sorted by sieving. The materials were finally converted to the acid form by immersing in $1 \mathrm{M} \mathrm{HNO}_{3}$, the acid being intermittently replaced, washed with conductivity water till free from acid and again dried at room temperature.

\subsection{Characterization}

The materials have been analysed for tin, titanium, zirconium and tungsten. Tin, titanium and zirconium were determined gravimetrically as oxides by the cupferron method ${ }^{9}$ whereas tungsten was determined as barium tungstate. ${ }^{10}$ Thermograms (TGA) were recorded on a Shimadzu DT-30 thermal analyser at a heating rate of $10^{\circ} \mathrm{C} \mathrm{min}^{-1}$. DSC of 
the samples were performed on a Melter TA 4000 system at a heating rate of $20^{\circ} \mathrm{C} \min ^{-1}$. FTIR spectra were recorded on a Bomen MB 104 series equipped with Epson Hi 80 printer/plotter. X-ray analyses of samples were carried out on a Rigaku Dmax-30 using $\mathrm{Cu}-\mathrm{K} \alpha$ radiation with a nickel filter. Chemical resistivity of the materials were assessed by soaking the exchangers in several mineral acids, bases and organic solvents. Ion exchange capacities (i.e.c.) of the materials were determined by the column method ${ }^{11}$ by taking $1 \mathrm{~g}$ of the exchanger in $\mathrm{H}^{+}$form in a glass column and eluting with $\mathrm{Na}^{+}$ions. The hydrogen ions thus eluted were determined titrimetrically against standard $\mathrm{NaOH}$.

\subsection{Conductivity measurements}

The protonic conductivities of the materials were measured using pellets of $14 \mathrm{~mm}$ diameter and 1.5-2 mm thickness. The opposite sides of the pellets were coated with conducting silver paste to ensure good electrical contact. Impedance measurements were taken using HP 4192 A impedance analyser over a frequency range of $5 \mathrm{~Hz}$ to $13 \mathrm{MHz}$ at a signal level below $1 \mathrm{~V}$, interfaced to a minicomputer for data collection. The measurements were made in the temperature range $30-175^{\circ} \mathrm{C}$. In all cases, since the impedance plots of the materials consist of single depressed semi-circles, the pellet conductivity was calculated by arc extrapolation to the $\mathrm{X}$-axis, taking into account the geometric size of the pellets.

\section{Results and discussion}

All the tungstates were hard and white except TiW which is yellow. The chemical resistivity of the materials $\mathrm{SnW}$, TiW and $\mathrm{ZrW}$ have been presented in table 1. As an illustration, for all the characterizations, the results for $\mathrm{SnW}$ have been shown, as all three tungstates show similar behaviour.

Chemical analyses of all three materials $\mathrm{SnW}, \mathrm{TiW}$ and $\mathrm{ZrW}$ indicate the metal (IV) to tungstate ratio to be $1: 2$.

Thermograms of $\mathrm{SnW}$ (figure 1), TiW and $\mathrm{ZrW}$ indicate 13, 14 and 15\% weight loss within the temperature range of $100-180^{\circ} \mathrm{C}$ corresponding to the loss of water molecules, after which a gradual weight loss is observed till $600^{\circ} \mathrm{C}$. This may be due to the condensation of structural hydroxyl groups. DSC (figure 2) of the tungstates shows only one exothermic peak at $\sim 132^{\circ} \mathrm{C}$ which is attributed to the presence of water. There is no endothermic peak up to $500^{\circ} \mathrm{C}$, which indicates that there is no phase change.

Table 1. Chemical resistivity of $\mathrm{SnW}$, TiW and $\mathrm{ZrW}$ in various media.

\begin{tabular}{llll}
\hline Medium & SnW & TiW & ZrW \\
\hline Acids & & & \\
$\mathrm{H}_{2} \mathrm{SO}_{4}$ & $36 \mathrm{~N}$ & $36 \mathrm{~N}$ & $3 \mathrm{~N}$ \\
$\mathrm{HCl}$ & $1 \mathrm{~N}$ & $11 \cdot 3 \mathrm{~N}$ & $3 \mathrm{~N}$ \\
$\mathrm{HNO}_{3}$ & $14 \mathrm{~N}$ & $14 \mathrm{~N}$ & $3 \mathrm{~N}$ \\
Bases & & & \\
$\mathrm{NaOH}$ & $0.5 \mathrm{M}$ & $0 \cdot 1 \mathrm{M}$ & $1 \mathrm{M}$ \\
$\mathrm{KOH}$ & $0.5 \mathrm{M}$ & $0 \cdot 1 \mathrm{M}$ & $1 \mathrm{M}$ \\
Organic solvents & All materials were found to be stable \\
\hline
\end{tabular}




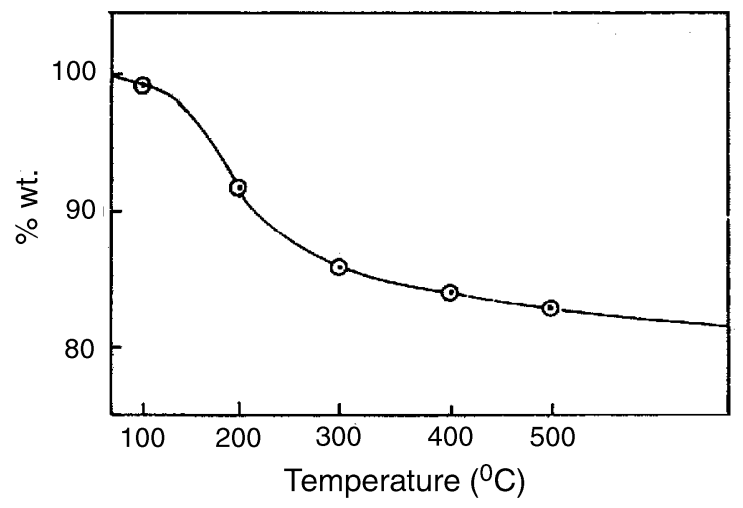

Figure 1. TGA of SnW.

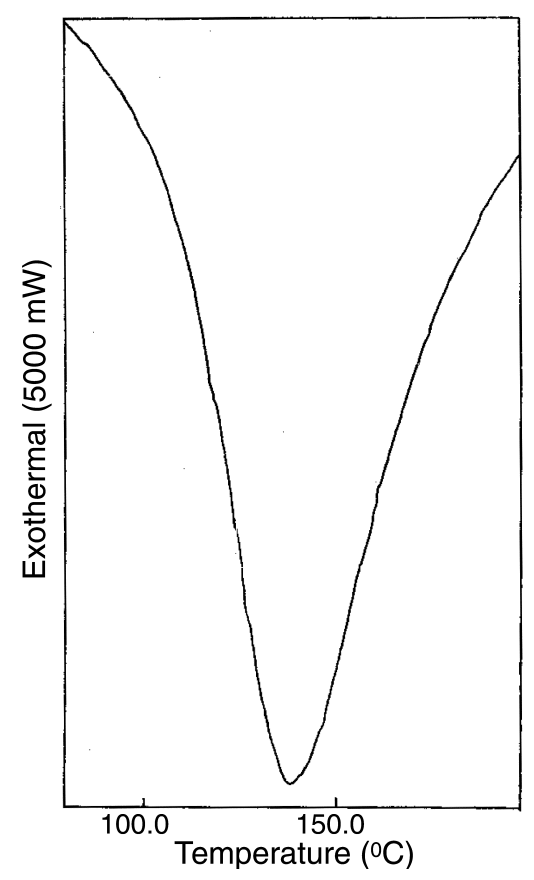

Figure 2. DSC of SnW.

The Alberti Torrocca formula ${ }^{12}$ has been used to determine the number of water molecules in SnW, TiW and $\mathrm{ZrW}$. From this data, along with gravimetric determination of $\mathrm{M}(\mathrm{IV})$ and tungsten (as their oxides) we could probably formulate the three materials $\mathrm{SnW}$, TiW and $\mathrm{ZrW}$ as $\mathrm{Sn}^{\mathrm{IV}}\left(\mathrm{W}^{\mathrm{VI}} \mathrm{O}_{2}(\mathrm{OH})_{2}\right) \cdot 5 \mathrm{H}_{2} \mathrm{O}$; $\mathrm{Ti}^{\mathrm{IV}}\left(\mathrm{W}^{\mathrm{VI}} \mathrm{O}_{2}(\mathrm{OH})_{2}\right) \cdot 6 \mathrm{H}_{2} \mathrm{O}$ and $\mathrm{Zr}^{\mathrm{IV}}\left(\mathrm{W}^{\mathrm{VI}} \mathrm{O}_{2}(\mathrm{OH})_{2}\right) .8 \mathrm{H}_{2} \mathrm{O}$.

FTIR spectra shows a broad band in the region $\sim 3400 \mathrm{~cm}^{-1}$ attributed to asymmetric and symmetric hydroxo -OH and aquo-OH stretches. A sharp medium band at $\sim 1620 \mathrm{~cm}^{-1}$ is attributed to aquo $(\mathrm{H}-\mathrm{O}-\mathrm{H})$ bending. 
$\mathrm{XRD}$ of the as prepared materials and materials calcined at $400^{\circ} \mathrm{C}$, do not exhibit any sharp peaks, indicative of non-crystalline nature of the materials.

The $\mathrm{Na}^{+}$exchange capacity for $\mathrm{SnW}$, TiW, and $\mathrm{ZrW}$ was found to be 1.52, 1.95 and 1.32 meq. $\mathrm{g}^{-1}$ respectively.

The effects of heating on ion exchange capacity, represented in table 2 reveal that, in general, ion exchange capacity decreases on heating. This may be due to the condensation of structural hydroxyl groups at higher temperatures. This fact is also evident from the FTIR spectra of the heated samples (figure 3). It is seen that the intensity of the peaks at $\sim 3400 \mathrm{~cm}^{-1}$ and $1620 \mathrm{~cm}^{-1}$, representative of the $-\mathrm{OH}$ group, and external water molecules respectively diminishes as heating temperature increases.

The results of specific conductance for $\mathrm{SnW}$, TiW, and $\mathrm{ZrW}$ have been presented in table 3. The complex impedance plots for all tungstates at $30^{\circ} \mathrm{C}$ have been presented (figure 4).

For all materials, it is observed that, specific conductivity decreases with increasing temperature (table 3). This is attributed to the loss of water of hydration as well as the condensation of structural hydroxyl groups with increasing temperature. This fact is also

Table 2. Effect of heating on ion exchange capacity of SnW, TiW and ZrW.

\begin{tabular}{|c|c|c|c|c|c|c|}
\hline \multirow[b]{2}{*}{ Temp. $\left({ }^{\circ} \mathrm{C}\right)$} & \multicolumn{3}{|c|}{ Colour } & \multicolumn{3}{|c|}{ Ion exchange capacity (meq. $\left.\mathrm{g}^{-1}\right)$} \\
\hline & SnW & TiW & $\mathrm{ZrW}$ & $\mathrm{SnW}$ & TiW & $\mathrm{ZrW}$ \\
\hline RT & White & Yellowish & White & 1.52 & 1.95 & $1 \cdot 32$ \\
\hline 100 & Yellowish & Yellowish & Yellowish & 1.08 & 1.90 & 0.49 \\
\hline 200 & Light brown & Yellowish & Light brown & $0 \cdot 82$ & 1.28 & $0 \cdot 24$ \\
\hline 300 & Brown & Dull green & Brown & 0.62 & 0.72 & $0 \cdot 22$ \\
\hline 400 & Brown & Dull green & White & $0 \cdot 50$ & $0 \cdot 26$ & $0 \cdot 16$ \\
\hline 500 & Brown & Dull green & White & $0 \cdot 39$ & $0 \cdot 21$ & $0 \cdot 10$ \\
\hline
\end{tabular}

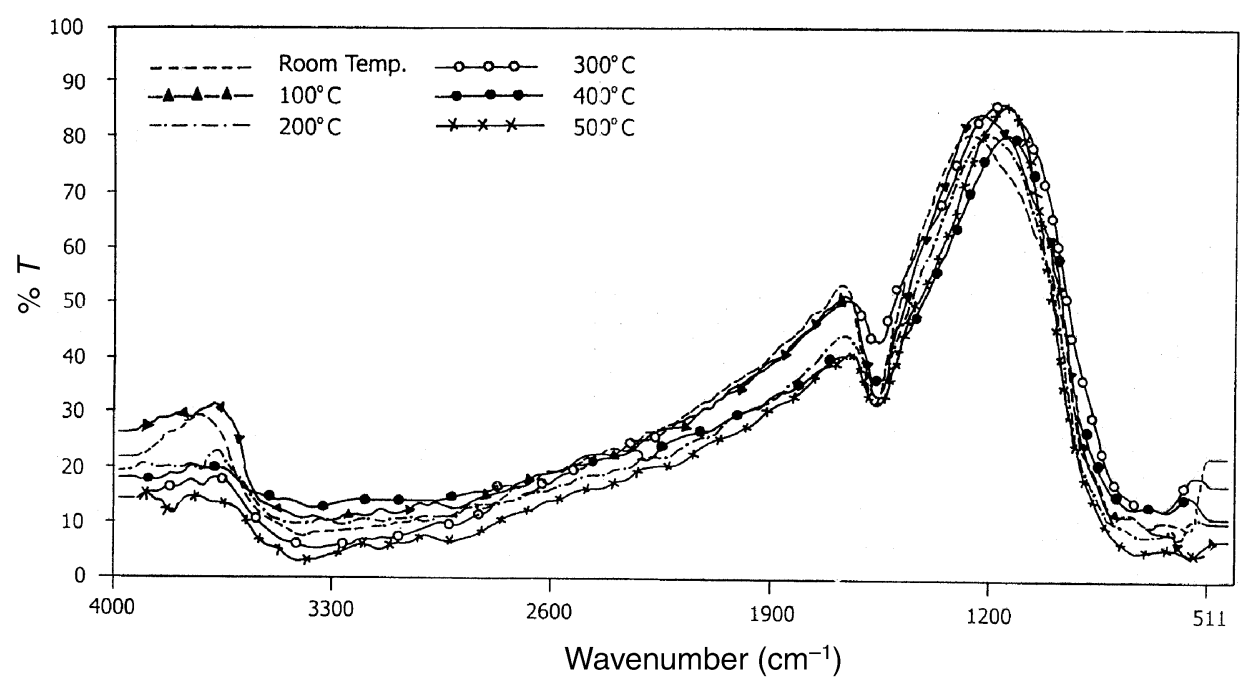

Figure 3. FTIR spectra of $\mathrm{SnW}$ and $\mathrm{SnW}$ heated at various temperatures. 

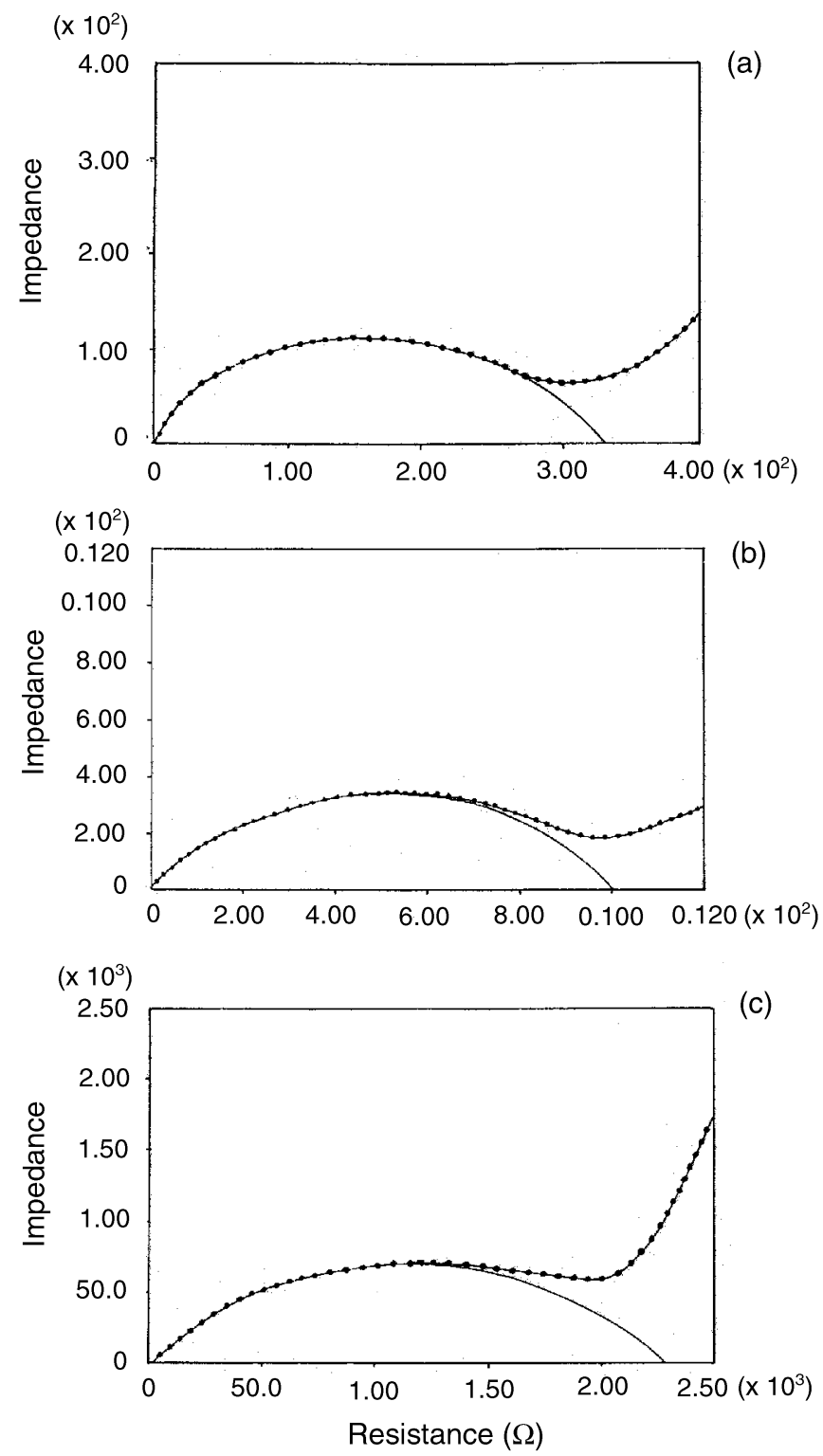

Figure 4. Complex impedance plots for (a) $\mathrm{SnW}$, (b) $\mathrm{TiW}$ and (c) $\mathrm{ZrW}$ at $30^{\circ} \mathrm{C}$.

supported by the study of effect of heating on ion exchange capacity and FTIR spectra of the heated samples (figure 3), as discussed above. This suggests the mechanism of transportation as Grotthus type ${ }^{13}$ where the conductivity depends on the ability of the water located on the surface to rotate and participate. Further, the results are also in agreement with the suggestion that protons are not able to diffuse along an anhydrous surface where the spacing of the $-\mathrm{OH}$ groups is too high. ${ }^{14}$ Besides, the fact that the loss of protons resulting from the hydroxyl condensation causes a considerable decrease in conductivity, indicates that the conduction is protonic also. 
Table 3. Variation of specific conductance $(\sigma)$ with temperature.

\begin{tabular}{lccc}
\hline & \multicolumn{3}{c}{$\sigma(\Omega \mathrm{cm})^{-1}$} \\
\cline { 2 - 4 } Temp. $\left({ }^{\circ} \mathrm{C}\right)$ & $\mathrm{SnW}\left(\times 10^{-4}\right)$ & $\mathrm{TiW}\left(\times 10^{-5}\right)$ & $\mathrm{ZrW}\left(\times 10^{-5}\right)$ \\
\hline 30 & $2 \cdot 166$ & 12.99 & $5 \cdot 220$ \\
40 & $2 \cdot 043$ & 10.39 & $5 \cdot 110$ \\
60 & 1.744 & $7 \cdot 026$ & 4.294 \\
80 & 1.554 & 5.415 & $3 \cdot 121$ \\
100 & 1.430 & 3.330 & 2.550 \\
120 & $1 \cdot 117$ & 2.825 & 2.500 \\
140 & 1.021 & 1.604 & 0.5227 \\
160 & 0.2040 & 0.4726 & 0.1878 \\
175 & 0.04300 & $0 \cdot 1768$ & 0.03699 \\
\hline
\end{tabular}
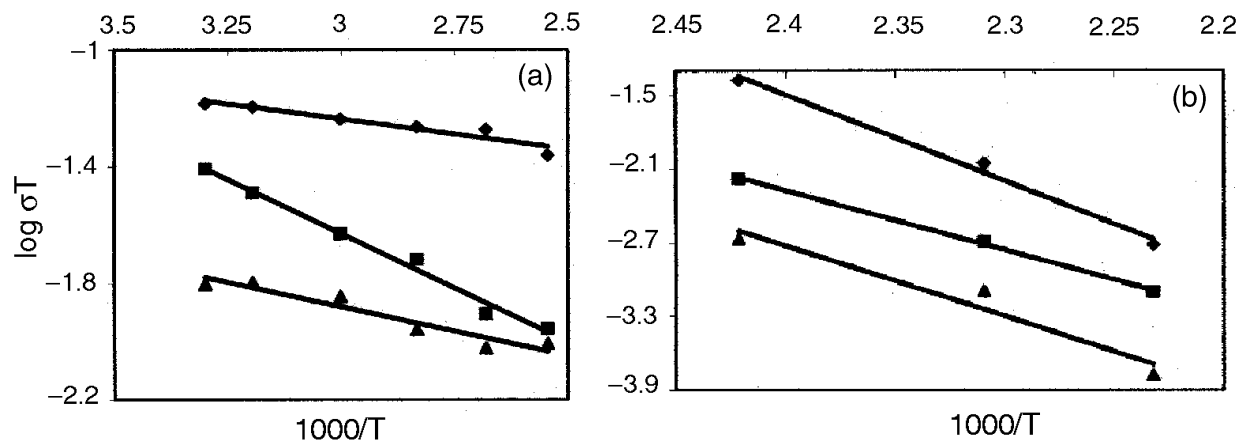

Figure 5. Arrhenius plot in the temperature range $30-120^{\circ} \mathrm{C}$ (a) and (b) $140-175^{\circ} \mathrm{C}$. $(\diamond \mathrm{SnW}, \boldsymbol{\mathrm { TiW }}, \boldsymbol{\Delta} \mathrm{ZrW})$.

Table 3 reveals the order of specific conductivity $(\sigma)$ at $30^{\circ} \mathrm{C}$ to be $\mathrm{SnW} \geq \mathrm{TiW}>\mathrm{ZrW}$. This trend is also in keeping with the ion exchange capacities of the tungstates that reflects on the proton conduction capacity. Arrhenius plots have been presented in (figure $5)$. For all the three materials linearity is observed in the temperature range $\left(30^{\circ} \mathrm{C}-\right.$ $\left.120^{\circ} \mathrm{C}\right)$ and $\left(140^{\circ} \mathrm{C}-175^{\circ} \mathrm{C}\right)$. The energy of activation has been calculated and found to be $0.41(\mathrm{SnW}), 1.47(\mathrm{TiW})$ and $0.66(\mathrm{ZrW})$ in the temperature range $30^{\circ} \mathrm{C}-120^{\circ} \mathrm{C}$, whereas it is found to be $13.92(\mathrm{SnW}), 9.65(\mathrm{TiW})$ and $11.41(\mathrm{ZrW})$ in the temperature range $\left(140^{\circ} \mathrm{C}-175^{\circ} \mathrm{C}\right)$. Further, specific conductivity values at $30^{\circ} \mathrm{C}$ for $\mathrm{SnW}$ and $\mathrm{TiW}$ are much higher than that of $\alpha-\mathrm{ZrP}^{15}\left(3.2 \times 10^{-6} \Omega^{-1} \mathrm{~cm}^{-1}\right)$ but are comparable to its modified forms like pellicular $\mathrm{ZrP}\left(1.1 \times 10^{-4} \Omega^{-1} \mathrm{~cm}^{-1}\right)^{16}$ and polyhydrated $\mathrm{ZrP}^{17}(2.7 \times$ $10^{-6} \Omega^{-1} \mathrm{~cm}^{-1}$ ) where the method of preparation is also rather difficult. The values of specific conductivity $(\sigma)$ for $\mathrm{SnW}$ and TiW are also comparable to that of amorphous polymer electrolyte blends. ${ }^{18}$

\section{Conclusion}

The present work is an attempt to establish the use of $\mathrm{SnW}$, TiW and $\mathrm{ZrW}$ as proton conductors. However, further studies have to be carried out to establish the various 
factors contributing to protonic conductivity such as role of the tetravalent metal M(IV) and the anion moiety e.g. phosphates, arsenates, molybdates etc. before making any final conclusions. Research in this line is being carried out in our laboratory.

\section{Acknowledgements}

The help rendered by Dr A R Kulkarni, Indian Institute of Technology, Mumbai in impedance measurements is gratefully acknowledged.

\section{References}

1. Alberti G and Casciola M 2001 Solid State Ionics 1453

2. Norby T 1999 Solid State Ionics 1251

3. Kreuer K D, Rabenau A and Weppner W 1982 Angew. Chem., Int. Ed. Engl. 21208

4. Ikawa H 1992 In Proton conductors (ed.) Ph Colamban (Cambridge: University Press) p. 190

5. Alberti G, Casciola M, Costantino U, Levi G and Riccardi G 1978 J. Inorg. Nucl. Chem. 40533

6. Alberti G, Casciola M, Costantino U and Radi R 1979 Gazz. Chim. Ital. 109179

7. Clearfield A and Berman J R 1981 J. Inorg. Nucl. Chem. 432141

8. Beena B and Chudasama U 1996 Bull. Mater. Sci. 19405

9. Elving Ph J and Olson E C 1955 Anal. Chem. 271817

10. Vogel A I 1978 Textbook of quantitative inorganic analysis 4th edn (London: Longman Green)

11. Nabi S A and Rao R K 1981 J. Indian Chem. Soc. 111030

12. Alberti G and Torracca E 1968 J. Inorg. Nucl. Chem. 303075

13. Clearfield A 1988 J. Mol. Catal. 88125

14. Aberti G, Costantino U and Palombari R 1989 First Int. Conf. on Inorganic Membranes, Régional Langu-doc Rousillon, Montpellier, France, p. 25

15. Casciola M and Bianchi D 1985 Solid State Ionics 17287

16. Alberti G, Casciola M, Costantino U and Leonardi M 1984 Solid State Ionics 14289

17. Alberti G, Casciola M, Costantino U and DiGregario F 1989 Solid State Ionics 32/33 44

18. Paulmer R D A and Kulkarni A R 1992 Solid state ionics: Materials and applications (ed.) B V R Chowdari (Singapore: World Scientific) p. 549 